\title{
Linkage Disequilibrium and Spatial Aggregation of Genotypes in Sexually Reproducing Populations of Erysiphe necator
}

\author{
Marin Talbot Brewer, Omer Frenkel, and Michael G. Milgroom
}

Department of Plant Pathology and Plant-Microbe Biology, Cornell University, Ithaca, NY 14853.

Current address of M. T. Brewer: Department of Plant Pathology, University of Georgia, Athens, GA 30602.

Current address of O. Frenkel: Agricultural Research Organization, The Volcani Center, P.O. Box 6, Bet-Dagan 50250, Israel.

Accepted for publication 18 June 2012.

ABSTRACT

\begin{abstract}
Brewer, M. T., Frenkel, O., and Milgroom, M. G. 2012. Linkage disequilibrium and spatial aggregation of genotypes in sexually reproducing populations of Erysiphe necator. Phytopathology 102:997-1005.

Random mating and recombination in heterothallic ascomycetes should result in high genotypic diversity, 1:1 mating-type ratios, and random associations of alleles, or linkage equilibrium, at different loci. To test for random mating in populations of the grape powdery mildew fungus Erysiphe necator, we sampled isolates from vineyards of Vitis vinifera in Burdett, NY (NY09) and Winchester, VA (VA09) at the end of the epidemic in fall 2009. We also sampled isolates from the same Winchester, VA vineyard in spring 2010 at the onset of the next epidemic. Isolates were genotyped for mating type and 11 microsatellite markers. In the spring sample, which originated from ascospore infections, nearly every isolate had a unique genotype. In contrast, fall populations were less diverse. In all, 9 of 45 total genotypes in VA09 were represented by two
\end{abstract}

or more isolates; 3 of 40 total genotypes in NY09 were represented by two or more isolates, with 1 genotype represented by 20 isolates. After clone correction, mating-type ratios in the three populations did not deviate from 1:1. However, even with clone correction, we detected significant linkage disequilibrium (LD) in all populations. Mantel tests detected positive correlations between genetic and physical distances within vineyards. Spatial autocorrelation showed aggregations up to 42 and $3 \mathrm{~m}$ in VA09 and NY09, respectively. Spatial autocorrelation most likely results from short dispersal distances. Overall, these results suggest that spatial genetic aggregation and clonal genotypes that arise during the asexual phase of the epidemic contribute to persistent LD even though populations undergo sexual reproduction annually.

Additional keywords: genetic neighborhood, mating systems, population genetics, selection.
Recombination resulting from sexual reproduction leads to new genotypes that permit organisms to better adapt to changing conditions and purges genomes of the accumulation of deleterious mutations (43). In numerous species of fungi, oomycetes, and plants, and some animals, sexual reproduction results in dormant propagules that permit these organisms to survive adverse conditions, such as drought or extreme temperatures. Many hypotheses have been presented on the advantages of sexual reproduction over asexual reproduction in the evolution of reproductive modes (30). However, there are also costs to sex, such as breaking up favorable allele combinations in stable environments (5), as well as the costs of finding a suitable mate and engaging in mating (2). An enormous diversity of mating systems and reproductive modes are found among fungi (18), yet it is not evident why such diverse reproductive modes are maintained. A mixed mode of reproduction involving regular sexual reproduction combined with multiple cycles of asexual reproduction is common among plantpathogenic fungi, bringing with it the advantages conferred by sexual reproduction while simultaneously allowing beneficial combinations to persist and increase through asexual reproduction. Populations with mixed reproductive modes may produce diverse genotypes from sexual reproduction but the fittest genotypes can increase in frequency rapidly because of clonal reproduction. This type of evolution, in which the fittest pathogen

Corresponding author: M. G. Milgroom; E-mail address: mgm5 @ cornell.edu

*The $\boldsymbol{e}$-Xtra logo stands for "electronic extra" and indicates that the online version contains one supplementary table.

http://dx.doi.org/10.1094/PHYTO-11-11-0321

(c) 2012 The American Phytopathological Society clones emerge rapidly in a selective sweep, has been termed an "epidemic" model of population structure (34). Among plant pathogens, mixed modes of reproduction have been hypothesized to lead to rapid evolution to overcome host resistance or develop resistance to fungicides (35).

In a randomly mating, or panmictic, population, all individuals are potential mates. In randomly mating fungal populations, we expect to find all mating types in equal frequencies. Additionally, recombination during meiosis should result in high genotypic diversity and random associations of alleles at different loci, which is referred to as linkage (or gametic) equilibrium (38). Nonrandom mating occurs due to inbreeding, where selfing is the most extreme form. Inbreeding can occur if genetically differentiated subpopulations are sampled and analyzed as if coming from a single undifferentiated population; this is known as the Wahlund effect (62). A more subtle form of population subdivision, which also results in nonrandom mating, is caused by short-distance dispersal and mating between individuals in small genetic neighborhoods. Short-distance dispersal prevents potential mates from mixing freely over long distances and results in a population structure known as isolation-by-distance, in which nonrandom mating and LD are evident at spatial scales larger than neighborhoods (66).

Although isolation by distance has been studied at relatively large spatial scales (kilometers and larger) for some plant pathogens $(39,52,54)$, spatial genetic structure has been studied at smaller scales (tens of meters) for relatively few species. Spatial autocorrelation of multilocus genotypes has been conducted for several fungal pathogens of trees in forests $(17,25,40,61)$. Spatial analyses of genotypic data have also been conducted for fungal pathogens of agronomic crops within fields ranging from a spatial 
scale of hundreds of meters to $1-\mathrm{m}$ rows $(6,14,29)$. The goals in these studies were to better understand dispersal, colonization, dormancy, or reproductive modes of the pathogens.

The grape powdery mildew fungus Erysiphe necator has a mixed mode of reproduction, with numerous cycles of asexual reproduction throughout the epidemic and regular sexual reproduction annually at the end of the epidemic (22). It is a heterothallic fungus $(24,36)$ and, thus, requires two individuals, each of a different mating type (MAT1-1 or MAT1-2), for sexual reproduction. The products of sexual reproduction are ascospores, which are produced in cleistothecia. Ascospores are an important source of primary inoculum in many regions $(13,49)$ and the only source of primary inoculum in regions with cold winters (49), as in this study. In milder climates, E. necator can also overwinter as dormant mycelium inside of buds which, in the spring, give rise to shoots covered with mycelium and conidia, known as flag shoots (50). In Europe and Australia, where E. necator has been introduced, populations are structured into two distinct genetic groups that appear to be reproductively isolated $(16,42,45,51,60)$ and, therefore, are not randomly mating. Recent studies of the population genetics of E. necator showed that genetic diversity is much greater in the eastern United States than in introduced populations in Europe, Australia, or the west coast of the United States, and that the eastern United States is the likely source for the introductions to these new areas $(9,21)$.

Gene flow of E. necator typically occurs by the dispersal of ascospores and conidia, although the fungus can also be dispersed on infected plant material for long-distance introductions. Conidia appear to have a steep dispersal gradient, dispersing mostly on the order of several meters (14). However, less is known about the distance that ascospores of E. necator disperse. It is generally assumed that both spore types are dispersed by extreme wind (26) or rain (23); however, whether or not gene flow is limited or longdistance has not been thoroughly investigated. Recent studies have shown large-scale geographic structure within eastern North America $(9,21)$, which suggests that gene flow is restricted to some extent. Both of these studies also showed evidence of recombination, and Frenkel et al. (21) found a lack of LD across broad geographic scales, albeit with relatively small samples.

We investigated larger samples from local populations of $E$. necator within single vineyards in the eastern United States to test whether random mating was occurring on a local scale, within vineyards. By focusing on this smaller scale (on the order of tens of meters), the genetic differentiation detected over large geographic scales (hundreds of kilometers or more) $(9,21)$ would not be a factor contributing to LD. The objectives of this study were to determine (i) if local populations of E. necator are randomly mating as we would expect, given they have an annual sexual cycle with no asexual overwintering in the locations of study; (ii) if genotypes of E. necator are spatially aggregated within vineyards; and (iii) if there is temporal or geographic divergence between populations.

\section{MATERIALS AND METHODS}

Sampling. We collected isolates of E. necator from two vineyards of Vitis vinifera 'Chardonnay' in fall 2009, at the end of the epidemic: a commercial vineyard in the Finger Lakes Region in Burdett, NY on 21 September 2009 (NY09) and a research vineyard at the Virginia Polytechnic Institute and State University, Alson H. Smith Jr. Agricultural Experiment Station in Winchester, VA on 12 October 2009 (VA09). For NY09, we sampled 100 leaves with powdery mildew colonies from 10 rows at 3-m intervals (10 isolates/row) (Fig. 1). The vineyard in Virginia differed in shape and size; therefore, the same spatial sampling scheme could not be conducted at both vineyards. For VA09, we sampled 100 leaves with powdery mildew colonies from three rows at $3-\mathrm{m}$ intervals (33 or 34 isolates/row). This research vineyard contained

\section{A VA09}

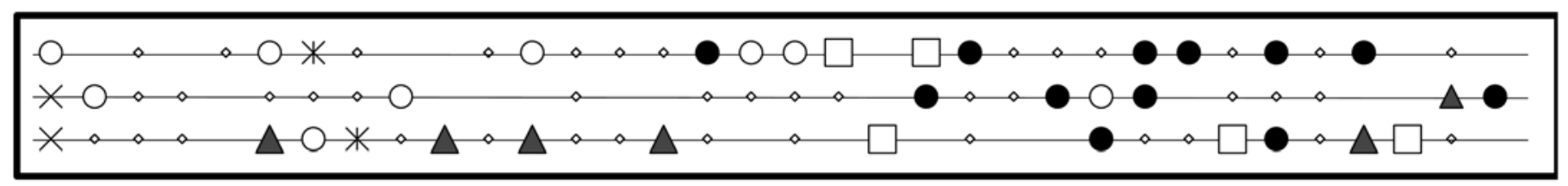

\section{B NY09}

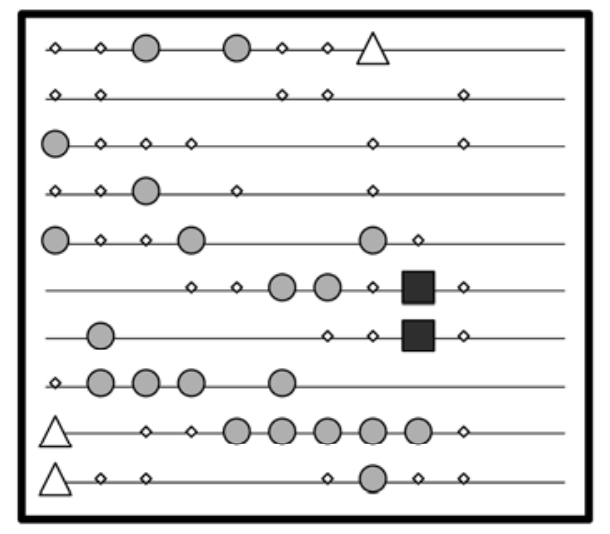

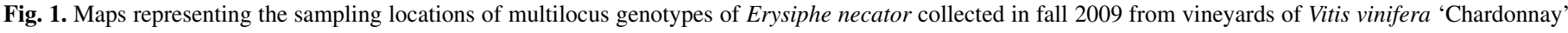

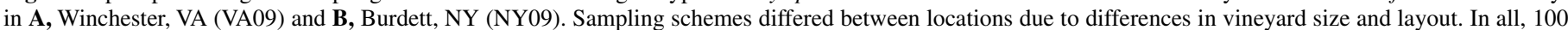

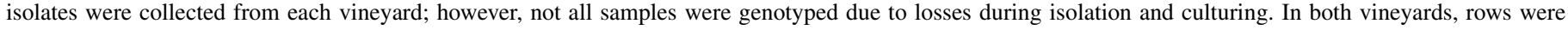

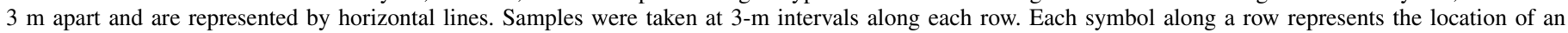

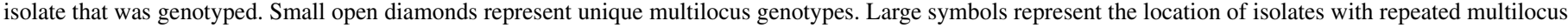

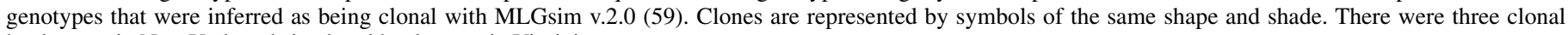
haplotypes in New York and six clonal haplotypes in Virginia. 
several plots of vines treated with different fungicides; however, we sampled from vines within each plot that were not sprayed. Rows were approximately $3 \mathrm{~m}$ apart in both vineyards. We recorded the locations of leaf samples within each vineyard for NY09 and VA09.

To understand the diversity of genotypes derived from sexual reproduction prior to multiple cycles of asexual reproduction, we collected isolates at the onset of the epidemic on 12 June 2010 from the Winchester, VA vineyard (VA10). Because flag shoots have not been observed in Virginia (M. Nita, personal communication), we assumed that colonies sampled at this time were derived from ascospore infections. Sampling for VA10 was done the same as described for VA09, except that the location of each sample was not recorded. Despite intensive efforts, we could not sample isolates from the New York vineyard (or other vineyards nearby) in spring 2010 because disease incidence was too low early in the season due to unfavorable environmental conditions and fungicide applications. By the time powdery mildew colonies were detectable in July, it was too late in the season for them to be representative of the overwintering sexual population because of asexual reproduction and selection for fungicide-resistant genotypes (65).

Isolation of $\boldsymbol{E}$. necator and DNA extraction. E. necator was isolated from powdery mildew colonies collected in the field onto surface-sterilized leaves of $V$. vinifera 'Cabernet Sauvignon', as described previously $(9,19)$. Young leaves from vines grown in a greenhouse were surface sterilized in $0.6 \%$ sodium hypochlorite for $1.5 \mathrm{~min}$, rinsed twice with sterile deionized water, and air dried in a sterile laminar flow hood. Leaves were kept in petri dishes containing $20 \mathrm{ml}$ of $2 \%$ water agar. Isolates were obtained by touching a single, isolated mildew colony on a leaf collected in the field to a surface-sterilized leaf. Single conidial chains were transferred to another surface-sterilized leaf after 2 to 3 weeks with a sterile pipet tip. Conidia from colonies arising from singleconidial chains were mass transferred to another surface-sterilized leaf for DNA extraction 2 to 4 weeks later.

Genomic DNA was prepared as described previously (9). Briefly, conidia and hyphae were collected from colonies by touching a $1-\mathrm{cm}^{2}$ piece of office tape (Scotch Tape; $3 \mathrm{M}$ ) to the colony multiple times until the tape was covered in fungal tissue. The tape was placed in a $1.5-\mathrm{ml}$ microcentrifuge tube with $100 \mu \mathrm{l}$ of $5 \%$ chelex $(28,63)$, vortexed for $30 \mathrm{~s}$, and incubated at $95^{\circ} \mathrm{C}$ for $20 \mathrm{~min}$. The solution was vortexed again for $5 \mathrm{~s}$ and centrifuged briefly, and the supernatant was removed and used as the DNA template for polymerase chain reaction (PCR).

Identification of mating-type. The mating type of each isolate was determined using a PCR-based marker (8). The amplified fragments of the PCR were predicted to be 408 bp for MAT1-1 and $232 \mathrm{bp}$ for MAT1-2. The PCR reaction was conducted in a total volume of $10 \mu \mathrm{l}$. Reaction components included $1 \mu \mathrm{l}$ of $10 \times$ PCR buffer (Takara); $1 \mu \mathrm{l}$ of dNTPs ( $2.5 \mathrm{mM}$ each); $0.5 \mu \mathrm{l}$ each of primers En $\alpha \mathrm{F} 2$, En $\alpha \mathrm{R} 3$, EnHMGF1, and EnHMGR1 $(10 \mu \mathrm{M})$; $0.3 \mathrm{U}$ of ExTaq (Takara); and $1 \mu \mathrm{l}$ (20 to $300 \mathrm{ng}$ ) of DNA template. Cycling conditions included an initial denaturation at $95^{\circ} \mathrm{C}$ for 2 min followed by 35 cycles with a denaturation step at $95^{\circ} \mathrm{C}$ for $30 \mathrm{~s}$, annealing at $55^{\circ} \mathrm{C}$ for $30 \mathrm{~s}$, and extension at $72^{\circ} \mathrm{C}$ for $30 \mathrm{~s}$; followed by a final extension at $72^{\circ} \mathrm{C}$ for $5 \mathrm{~min}$. Ten microliters of each PCR product with loading dye was analyzed by electrophoresis through a $1 \%(\mathrm{wt} / \mathrm{vol})$ agarose/Tris-borate-EDTA gel.

Multilocus genotyping. The genotype of each isolate was determined by using 11 expressed sequence tag (EST) simplesequence repeats (SSRs) (21). The microsatellite markers used included EnMS1-EnMS7 and EnMS9-EnMS11, and a new marker described here, EnMS12. EnMS12 was identified and developed in the same manner as the other EST-SSRs described by Frenkel et al. (21). The contig that was identified in E. necator isolate G14 contained the microsatellite repeat motif $(\mathrm{CTT})_{8}$. The PCR primers for EnMS12 are EnMS12F: 5'-CACGACGTTGTAAA ACGACCGCTCGTGCATCTTTATTGA- $3^{\prime}$, which includes M13specific sequence (underlined) at the $5^{\prime}$ end for multiplexing with other markers using fluorescent dyes as described previously (55), and EnMS12R: 5'-CGTGAAGCCCAAAGATAAGC-3'. PCR and fragment analysis were carried out as described previously (21). Briefly, PCR for all primer pairs was carried out in a total volume of $12.5 \mu \mathrm{l}$. Reactions included $1.25 \mu \mathrm{l}$ of $10 \times$ PCR buffer (Takara), $1.25 \mu \mathrm{l}$ of $2.5 \mathrm{mM}$ dNTPs, $0.2 \mu \mathrm{l}$ of $10 \mu \mathrm{M}$ forward primer, $0.4 \mu \mathrm{l}$ of $10 \mu \mathrm{M}$ reverse primer, $0.5 \mu \mathrm{l}$ of $10 \mu \mathrm{M} 5^{\prime}$-dyelabeled M13 primer (FAM, VIC, or NED; Applied Biosystems), $0.375 \mathrm{U}$ of ExTaq (Takara), and $1 \mu \mathrm{l}$ of DNA template (20 to $300 \mathrm{ng}$ ). Cycling conditions were the same as described above for mating type. For fragment analysis, PCR products from two or three reactions, each with a different fluorescent dye (FAM, VIC, or NED), were pooled and $1 \mu \mathrm{l}$ of the pooled reactions was added to $8.5 \mu \mathrm{l}$ of HIDI formamide (Applied Biosystems), $0.3 \mu \mathrm{l}$ of double-distilled $\mathrm{H}_{2} \mathrm{O}$, and $0.2 \mu \mathrm{l}$ of GeneScan $500 \mathrm{LIZ}$ size standard (Applied Biosystems) and heated for $5 \mathrm{~min}$ at $95^{\circ} \mathrm{C}$. Fragment analyses were conducted at the Cornell University Life Sciences Core Laboratories Center using an Applied Biosystems 3730xl DNA Analyzer. Allele sizes were analyzed using the GeneMapper Software (v3.0; Applied Biosystems). The range of allele sizes for EnMS12, including the M13-specific sequence, was 188 to $200 \mathrm{bp}$. Four alleles with sizes of 188, 191, 197, and $200 \mathrm{bp}$ were observed among the three populations. Allele sizes of the other EST-SSRs were described previously (21).

Analyses for random mating. Data were clone corrected for some analyses to eliminate the effects of asexual reproduction on tests for random mating. The same multilocus genotypes can arise more than once by recombination, depending on the number of markers used and the diversity of alleles at each locus. Therefore, to determine which repeated multilocus genotypes could be inferred as clonal and should be clone corrected, we estimated the probability that each multilocus genotype that was sampled more than once could have arisen by sex $\left(p_{\text {sex }}\right)$. These estimates are based on two probabilities $(4,46)$. First, the probability that each multilocus genotype can arise by chance in a randomly mating population, $p_{\text {gen }}$, is estimated as the product of the observed allele frequencies within each vineyard at each locus genotyped because E. necator is haploid. Second, the probability of encountering a specific multilocus genotype $x$ times in a sample of size $N$ is a binomial probability,

$$
\operatorname{Pr}\{X=x\}=\left(\begin{array}{l}
N \\
x
\end{array}\right) p_{\text {gen }}^{x}\left(1-p_{\text {gen }}\right)^{N-x}
$$

where $p_{\text {gen }}$ is the probability of the multilocus genotype occurring independently. Probability $p_{\text {sex }}$ was estimated using the program MLGsim v.2.0 (59). The $P$ value for testing the significance of $p_{\text {sex }}$ for each repeated multilocus genotype was estimated by simulating 1,000 randomly mating populations of size $N$ using observed allele frequencies to generate a null distribution of $p_{\text {sex }}$ against which the actual value of $p_{\text {sex }}$ could be compared.

Mating-type distributions of uncorrected and clone-corrected samples were tested for deviation from expected ratios of $1: 1$ using chi-square goodness-of-fit tests. Genotypic diversity $(\hat{G})$, the probability that two individuals taken at random have unique multilocus genotypes, was estimated for each population. $\widehat{G}$ is estimated as $[N /(N-1)]\left(1-\Sigma p_{\mathrm{i}}{ }^{2}\right)$, where $p_{\mathrm{i}}$ is the frequency of the $i$ th multilocus genotype and $N$ is the sample size for each population. Multilocus LD was determined for each uncorrected and clone-corrected sample using the index of association $\left(I_{\mathrm{A}}\right)$ $(10,34)$ and $\overline{r_{d}}$, estimated with MultiLocus v.1.3b (1): $I_{\mathrm{A}}=s_{\mathrm{k}}{ }^{2} /{\sigma_{\mathrm{k}}}^{2}-$ 1 , where $k$ is the number of loci at which pairs of individuals have different alleles, $s_{\mathrm{k}}{ }^{2}$ is the observed variance of $k$, and $\sigma_{\mathrm{k}}{ }^{2}$ is the expected variance of $k$ under linkage equilibrium. $I_{\mathrm{A}}$ is not significantly different from zero when the population is in linkage equilibrium. $P$ values were estimated by 1,000 random permu- 
tations of the data. The magnitude of $I_{\mathrm{A}}$ can increase with the number of loci studied; therefore, we used $\overline{r_{d}}$, which is a standardized measure of $I_{\mathrm{A}}$ for comparing LD among populations that vary by the number of polymorphic loci analyzed. Significance testing for LD between pairs of polymorphic loci was done with GENEPOP v.4.0 (53). Bonferroni correction was applied to account for multiple comparisons. Significance of linkage disequilibrium for each pair was evaluated at the overall type I error rate, $\beta=\alpha / n$, where $\alpha$ is the chosen level of significance for a single comparison and $n$ is the total number of comparisons.

Spatial genetic analyses. Mantel tests for matrix correspondence $(33,56)$ were conducted in GenAlEx v.6.41 (47) to determine if a significant relationship existed between genetic and physical distances of isolates in vineyard populations of $E$. necator (samples NY09 and VA09). Genetic distances between isolates were calculated as the sum of differences between genotypes where the same allele at a locus yields a value of 0 and a different allele yields a value of 1 . A Mantel test provides a correlation coefficient $\left(R_{x y}\right)$ for the two data matrices of pairwise genetic and physical distances between isolates. $P$ values were determined by comparing the frequency distribution of 1,000 random permutations with the original data.

To determine whether clusters of similar genotypes of $E$. necator existed within vineyards, spatial autocorrelation based on the methods of Smouse and Peakall (57) was performed in GenAlEx v.6.41 on the NY09 and VA09 samples. The autocorrelation coefficient, $r$, is a measure of the genetic similarity of pairs of isolates within specified distance classes. If the observed $r$ is greater or less than the $95 \%$ confidence interval about the null hypothesis of no spatial genetic structure, determined by the distribution of 1,000 random permutations of the data, it indicates local spatial genetic structure within the distance class. To account for spatial organization without the influence of repeated multilocus genotypes, the central spatial coordinate of each repeated multilocus genotype was used for autocorrelation analyses in the program GenClone v.1 (3). Autocorrelation with and without repeated multilocus genotypes was measured as the kinship coefficient, $F_{i j}$, proposed by Loiselle (32), which is similar to $r$ and is a measure of the genetic similarity of pairs of isolates within specified distance classes. $P$ values were estimated by randomly permuting genotypes to sampling locations.

Population structure analyses. Nei's genetic identity $(I)(44)$ and genetic differentiation $\left(\Phi_{\mathrm{PT}}\right.$, an analog of $F_{\mathrm{ST}}$ measured via analysis of molecular variance) (48) were determined among NY09, VA09, and VA10 samples using GenAlEx v.6.41 on full data sets. Significant differentiation between populations was determined by comparing observed values to the distribution of 1,000 randomizations of the data. Principal coordinates analysis was conducted with GenAlEx v.6.41 on pairwise genetic distances between all genotypes in order to visualize major patterns of variation within and among populations.

\section{RESULTS}

Genotyping and clonal composition of vineyard populations. Of 11 EST-SSR markers, 10 were used for analyses in each of the populations. Allele frequencies and unbiased gene diversity (h) for loci in each of the three populations are listed in the Supplementary Table. The marker EnMS1 was excluded from analyses of the NY09 population because we found two different size ranges among 10 alleles; therefore, it was considered hypervariable and unreliable for interpreting that all fragments came from a single locus and that alleles of the same size were identical by descent (21). However, only four alleles within a small size range were detected at EnMS1 for the VA09 and VA10 populations; therefore, it was not excluded from these analyses. The marker EnMS4, however, was excluded from the VA09 and VA10 analyses due to inconsistent PCR amplification.

We obtained 62, 78, and 69 isolates for NY09, VA09, and VA10, respectively (Table 1; Fig. 1), rather than the 100 originally sampled because colonies were not viable or isolates were lost prior to DNA extraction. Genotypic diversity was 0.897 to 0.996 . A large proportion of the isolates sampled from the vineyards in the fall (NY09 and VA09) were clones (Tables 1 and 2). All individuals in NY09 and VA10 with identical multilocus microsatellite genotypes had the same mating type; however, individuals with two of the multilocus microsatellite genotypes identified more than once in VA09 were represented by both mating types and were considered different genotypes overall. A single clone, comprising 20 of the 62 isolates sampled in NY09, dominated the population. We found nine genotypes with two or more isolates in VA09. The four most common clones were repre-

TABLE 2. Probabilities of multilocus genotypes (MLGs) of Erysiphe necator $\left(p_{\text {gen }}\right)$ and their reoccurrence resulting from distinct sexual events $\left(p_{\text {sex }}\right)$ within vineyards in Burdett, NY sampled in fall 2009 (NY09) and Winchester, VA sampled in fall 2009 (VA09) and spring 2010 (VA10)

\begin{tabular}{lcccc}
\hline $\begin{array}{l}\text { Population, } \\
\text { MLG }^{\mathrm{a}}\end{array}$ & $\begin{array}{c}\text { Number of } \\
\text { isolates }\end{array}$ & $p_{\text {gen }}{ }^{\mathrm{c}}$ & $p_{\text {sex }}{ }^{\mathrm{d}}$ & $\begin{array}{c}P \text { value } \\
\text { for } p_{\text {sex }}\end{array}$ \\
\hline NY09 & & & & \\
1 & 20 & $5.1 \times 10^{-3}$ & $3.1 \times 10^{-15}$ & $<0.001$ \\
2 & 3 & $1.2 \times 10^{-6}$ & $7.0 \times 10^{-14}$ & $<0.001$ \\
3 & 2 & $1.3 \times 10^{-5}$ & $3.0 \times 10^{-7}$ & 0.006 \\
VA09 & & & & \\
1 & 12 & $5.6 \times 10^{-4}$ & $4.0 \times 10^{-15}$ & $<0.001$ \\
2 & 9 & $2.6 \times 10^{-3}$ & $7.8 \times 10^{-13}$ & $<0.001$ \\
3 & 6 & $2.4 \times 10^{-5}$ & $2.2 \times 10^{-16}$ & $<0.001$ \\
4 & 5 & $1.6 \times 10^{-3}$ & $2.1 \times 10^{-7}$ & 0.004 \\
5 & 2 & $7.2 \times 10^{-6}$ & $1.6 \times 10^{-7}$ & 0.004 \\
6 & 2 & $3.7 \times 10^{-5}$ & $4.0 \times 10^{-6}$ & 0.014 \\
7 & 2 & $3.5 \times 10^{-4}$ & $3.5 \times 10^{-4}$ & 0.210 \\
8 & 2 & $3.2 \times 10^{-4}$ & $3.1 \times 10^{-4}$ & 0.118 \\
9 & 2 & $2.9 \times 10^{-4}$ & $2.5 \times 10^{-4}$ & 0.168 \\
VA10 & & & & \\
1 & 2 & $2.8 \times 10^{-6}$ & $1.8 \times 10^{-8}$ & $<0.001$ \\
2 & 2 & $9.8 \times 10^{-5}$ & $2.3 \times 10^{-5}$ & 0.203 \\
\hline
\end{tabular}

a Population and repeated MLGs. Each unique genotype was determined with 10 microsatellite markers and mating type.

b Number of isolates in each repeated genotype.

c Probability of the MLG occurring in the population and is calculated as the product of the allele frequencies.

${ }^{d}$ Probability of obtaining the observed number of identical genotypes in the population as a result of random mating $(4,46) \cdot p_{\mathrm{sex}}$ and its significance were estimated using the program MLGsim v.2.0 (59).

TABLE 1. Clonal composition of populations of Erysiphe necator in vineyards in Burdett, NY sampled in fall 2009 (NY09) and Winchester, VA sampled in fall 2009 (VA09) and spring 2010 (VA10)

\begin{tabular}{|c|c|c|c|c|c|c|}
\hline Population & $N$ & $g^{\mathrm{a}}$ & $\widehat{G}^{\mathrm{b}}$ & Repeated fraction $^{\mathrm{c}}$ & $g_{2}{ }^{\mathrm{d}}$ & Number of isolates in each repeated genotype \\
\hline NY09 & 62 & 40 & 0.897 & 0.36 & 3 & $20,3,2$ \\
\hline VA09 & 78 & 45 & 0.923 & 0.42 & 9 & $12,9,6,5,2,2,2,2,2$ \\
\hline VA10 & 69 & 67 & 0.996 & 0.03 & 2 & 2,2 \\
\hline
\end{tabular}

\footnotetext{
a Number of multilocus genotypes.

${ }^{\mathrm{b}}$ Genotypic diversity $(\widehat{G})=[N /(N-1)]\left(1-\Sigma p_{\mathrm{i}}{ }^{2}\right)$, where $p_{\mathrm{i}}$ is the frequency of the $i$ th genotype and $N$ is the sample size.

c Repeated fraction $=1-(\mathrm{g} / \mathrm{N})$.

d Number of genotypes represented by two or more isolates.
} 
sented by 12, 9, 6, and 5 isolates among a total of 78 isolates; five additional repeated genotypes in VA09 each had 2 isolates. Based on estimates and significance of $p_{\text {sex }}$, we could not reject the null hypothesis that three of these genotypes with two isolates arose independently by recombination (Table 2). In the spring sample (VA10), we found 67 multilocus genotypes among 69 isolates, with 2 genotypes each with 2 isolates. One of the repeated genotypes likely arose from sexual reproduction (Table 2), whereas the other is likely to have resulted from clonal reproduction.

Analyses of random mating. Mating-type ratios did not differ significantly from 1:1 $(P>0.05)$, except for the NY09 uncorrected sample (Table 3). A clone that occurred at high frequency in this population was MAT1-2, which skewed the mating-type ratio. After clone correction, the NY09 population did not deviate from 1:1, although sample size and statistical power to detect deviations were reduced accordingly.

Multilocus LD $\left(I_{\mathrm{A}}\right.$ and $\left.\overline{r_{d}}\right)$ was significantly greater than zero within each population $(P<0.001)$. Estimates of $I_{\mathrm{A}}$ and $\overline{r_{d}}$ were higher in fall populations with a high frequency of clones (NY09 and VA09) than in the spring population (VA10). Multilocus LD was reduced by clone correction in these populations; however, values remained significant $(P<0.001)$. Of the 45 pairs of loci in each population, there was significant $(P \leq 0.05)$ pairwise LD between $8(18 \%), 35(78 \%)$, and $37(82 \%)$ pairs of loci in the clone-corrected samples of the NY09, VA09, and VA10 populations, respectively. With Bonferroni correction $(\beta=\alpha / n=0.001$, for $\alpha=0.05, n=45$ ), there was no significant pairwise disequilibrium detected in the NY09 population, but 9 (20\%) and 17 (38\%) pairs of loci showed significant $(P<0.001)$ LD in the clone-corrected VA09 and VA10 samples respectively.

Spatial autocorrelation of genotypes. Spatial autocorrelation analyses indicated that spatial genetic structure exists within vineyard populations of E. necator. Mantel tests showed significant correlations between genetic distance and geographic distance in NY09 $\left(R_{x y}=0.082 ; P=0.027\right)$ and VA09 $\left(R_{x y}=0.282\right.$; $P=0.001)$. Isolates were more genetically similar to each other than expected at random in the smaller distance classes (Fig. 2). With the entire VA09 dataset, isolates in distance classes of $\leq 24$ or $\leq 39 \mathrm{~m}$ based on $r$ or $F_{i j}$, respectively, were more similar to each other than expected at random $(P \leq 0.05)$. Conversely, isolates in distance classes of 40 to $87 \mathrm{~m}$ or distance classes $57 \mathrm{~m}$ based on $r$ or $F_{i j}$, respectively, were less similar to each other than expected at random (Fig. 2A). With the entire NY09 dataset, only isolates in the smallest distance class $(3 \mathrm{~m})$ were more similar than expected at random in both analyses (Fig. 2B). We still detected significant spatial autocorrelation of genetic similarities in distance classes up to $42 \mathrm{~m}$ in VA09 when clones were accounted for by using the central coordinate of repeated multilocus genotypes (Fig. 2A). However, no spatial autocorrelation was detected in NY09 when replicate genotypes were removed.
The slope of the regression of the correlation between genetic distance and geographic distance for VA09 was $-0.019(P<$ 0.001) for both the entire data set and the analysis without the repeated multilocus genotypes. The slopes for NY09 were -0.003 $(P=0.11)$ and $-0.004(P=0.14)$ for the entire data set and without repeated multilocus genotypes, respectively.

Population structure. The loci EnMS1 and EnMS4 were removed from analyses comparing the NY09 and VA09 or VA10 populations because they were only genotyped in one or the other

A

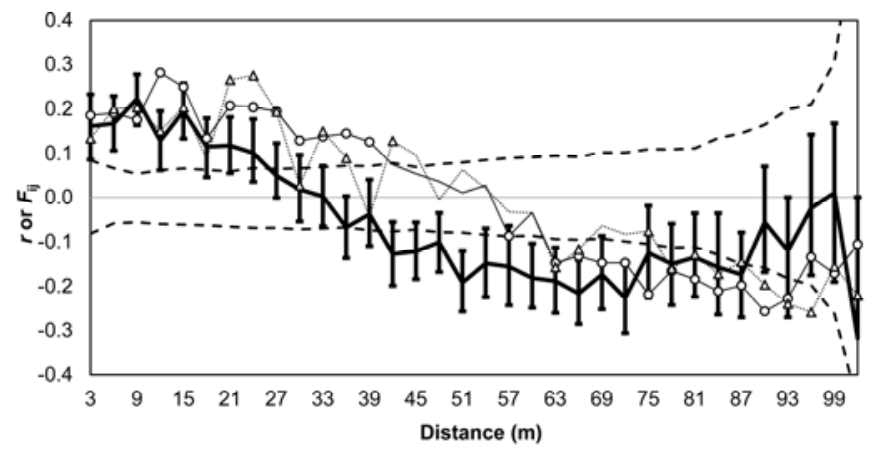

B

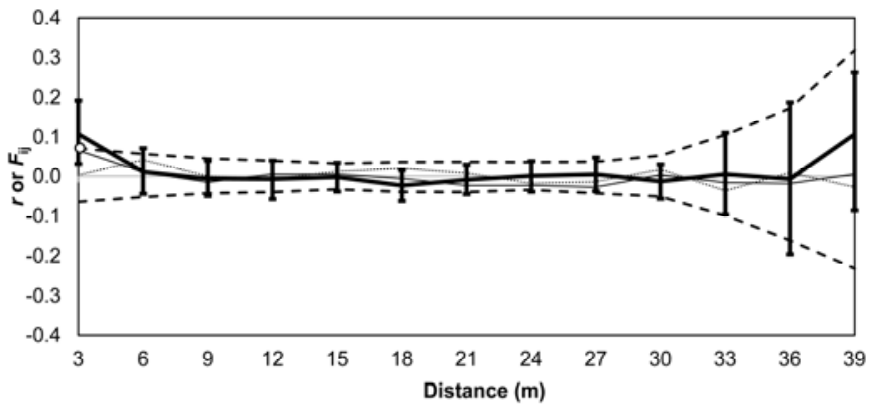

Fig. 2. Spatial autocorrelation analyses of vineyard populations of Erysiphe necator shown as correlograms for A, Winchester, VA (VA09) and B, Burdett, NY (NY09) sampled in fall 2009. The autocorrelation coefficient $r$, indicated by the heavy solid line with error bars, is a measure of the standardized pairwise genetic similarity of isolates within the corresponding distance class. The 95\% confidence intervals for the null hypotheses of random spatial genetic structure based on 1,000 permutations of the data are represented by dashed lines. Observed $r$ values outside of the 95\% confidence interval indicate significant spatial structure for the corresponding distance class. Kinship coefficients $\left(F_{\mathrm{ij}}\right)$ are depicted by a thin solid line or a dotted line for values with and without repeated multilocus genotypes, respectively. Open circles or triangles along the lines indicate significant $F_{\mathrm{ij}}$ values that are more or less similar than expected at random $(P<0.05)$ for analyses with and without repeated multilocus genotypes, respectively.

TABLE 3. Mating-type distributions and multilocus linkage disequilibrium for populations of Erysiphe necator in vineyards in Burdett, NY sampled in fall 2009 (NY09) and Winchester, VA sampled in the fall 2009 (VA09) and spring 2010 (VA10)

\begin{tabular}{|c|c|c|c|c|c|c|}
\hline \multirow[b]{2}{*}{ Population $^{\mathrm{a}}$} & \multirow[b]{2}{*}{$N$} & \multicolumn{2}{|c|}{ Mating-type distributions ${ }^{b}$} & \multicolumn{3}{|c|}{ Multilocus linkage disequilibrium $^{c}$} \\
\hline & & MAT1-1 & MAT1-2 & $\chi^{2}$ & $I_{\mathrm{A}}$ & $\overline{r_{d}}$ \\
\hline \multicolumn{7}{|l|}{ NY09 } \\
\hline Uncorrected sample & 62 & 17 & 45 & $12.64 * *$ & 1.49 & 0.17 \\
\hline \multicolumn{7}{|l|}{ VA09 } \\
\hline Uncorrected sample & 78 & 37 & 41 & 0.20 & 1.70 & 0.19 \\
\hline Clone-corrected sample & 48 & 23 & 25 & 0.08 & 1.05 & 0.12 \\
\hline
\end{tabular}

${ }^{a}$ Clone-corrected samples include a single representative of each multilocus genotype. Exceptions are for three multilocus genotypes from VA09 and one multilocus genotype from VA10 that were each repeated twice and were not inferred as clonal genotypes.

${ }^{\mathrm{b}}$ Asterisks $(* *)$ indicate that mating-type ratios deviated from 1:1 $(P \leq 0.001)$. $P$ values for all other samples are $>0.05\left(\chi^{2}<3.84\right)$.

${ }^{\mathrm{c}}$ Index of association $\left(I_{\mathrm{A}}\right)$ and $\overline{r_{d}}$ were calculated with MultiLocus v.1.3b (1). All $P$ values are $<0.001$ and were determined by 1,000 randomizations. 
population, as described above. No significant genetic differentiation $\left(\Phi_{\mathrm{PT}}\right)$ was detected between the New York and Virginia populations (Table 4). No differentiation was detected between the Virginia fall (VA09) and spring (VA10) populations. VA09 and VA10 were more similar to each other, as measured by Nei's genetic identity, than NY09 was to either VA09 or VA10. Principal coordinates analysis revealed considerable overlap among multilocus genotypes from all three populations (Fig. 3). The first two coordinates explained $55.9 \%$ of the variation. Overall, the genotypes formed a continuous group and no distinct patterns were evident. There was more overlap among genotypes from the fall (VA09) and spring (VA10) populations from Virginia than with genotypes from the NY09 population.

\section{DISCUSSION}

We tested the hypothesis that populations of E. necator are randomly mating within vineyards. As predicted for random mating, genotypic diversity in the three populations was high and mating-type ratios on clone-corrected data did not deviate significantly from $1: 1$. These results are consistent with the biology of E. necator because sexual reproduction occurs regularly and ascospores are the source of primary inoculum each season, especially in cold climates, as in this study, where ascospores are the only form of overwintering inoculum (49). In contrast to predictions under the hypothesis of random mating, however, significant LD was detected in all three populations. LD is not

TABLE 4. Geographic and temporal genetic differentiation, measured by $\Phi_{\mathrm{PT}}$ (above the diagonal) and Nei's genetic identity (below the diagonal) between vineyard populations of Erysiphe necator in Burdett, NY sampled in fall 2009 (NY09) and Winchester, VA sampled in fall 2009 (VA09) and spring 2010 $(\mathrm{VA} 10)^{\mathrm{a}}$

\begin{tabular}{lccc}
\hline & \multicolumn{3}{c}{ Population } \\
\cline { 2 - 4 } Population & VA09 & VA10 & NY09 \\
\hline VA09 & $\ldots$ & $0.001(0.448)$ & $0.02(0.087)$ \\
VA10 & 0.98 & $\ldots$ & $0.001(0.357)$ \\
NY09 & 0.80 & 0.78 & $\ldots$ \\
\hline
\end{tabular}

${ }^{\text {a }} P$ values for $\Phi_{\mathrm{PT}}$ are in parentheses; $\Phi_{\mathrm{PT}}$, an analog of $F_{\mathrm{ST}}$ measured via analysis of molecular variance (48), was determined using GenAlEx v.6.41 (47). expected among neutral markers in populations that undergo regular sexual reproduction because recombination breaks down LD. The LD observed in these populations is most likely the result of asexual reproduction; E. necator typically has $\geq 10$ asexual generations per year. Clones were prevalent in populations at the end of epidemics in both vineyards after multiple asexual generations but were rare in the one vineyard sampled early in the epidemic. Variation in frequencies among clonal genotypes, caused either by differential fitness or random colonization events, could result in LD, as explained further below.

For pathogens with mixed modes of reproduction (i.e., both sexual and asexual generations occur on regular cycles), clone correction is a way of inferring the underlying genetic structure caused by sexual reproduction $(34,41)$. Clone correction is valid as long as the probability of the same genotype occurring more than once due to an independent sexual reproduction event $\left(p_{\text {sex }}\right)$ is small. In all populations of E. necator in this study, $p_{\text {sex }}$ was significant for the majority of genotypes sampled more than once, indicating a significant contribution by clonal reproduction. Yet, not all fungi with a mixed mode of reproduction show LD within populations, including Gibberella zeae (67). For some fungal plant pathogens, clone correction reduces LD to insignificant levels; for example, Cryphonectria parasitica (41) and Mycosphaerella graminicola (68). LD after clone correction has been detected in other plant-pathogenic ascomycetes with a mixed mode of reproduction $(7,11,15)$. The observation that clone correction did not eliminate LD in populations of E. necator in this study suggests that LD is caused by factors other than asexual reproduction alone.

LD may be caused by a variety of processes besides nonrandom mating (including asexual reproduction), such as epistatic selection (20), hitch-hiking selection, admixture of genetically different populations, or physical linkage among markers (27). Epistatic selection, which favors combinations of alleles at different loci that are advantageous, can cause LD in randomly mating populations if selection is strong compared with the recombination breaking up associations among alleles. Epistatic selection has been suggested as a possible cause of LD in the barley powdery mildew fungus Blumeria graminis f. sp. hordei, where the use of resistant cultivars and selective fungicides favored specific combinations of avirulence and fungicide resistance alleles $(11,64)$. Selection for avirulence or fungicide resis-

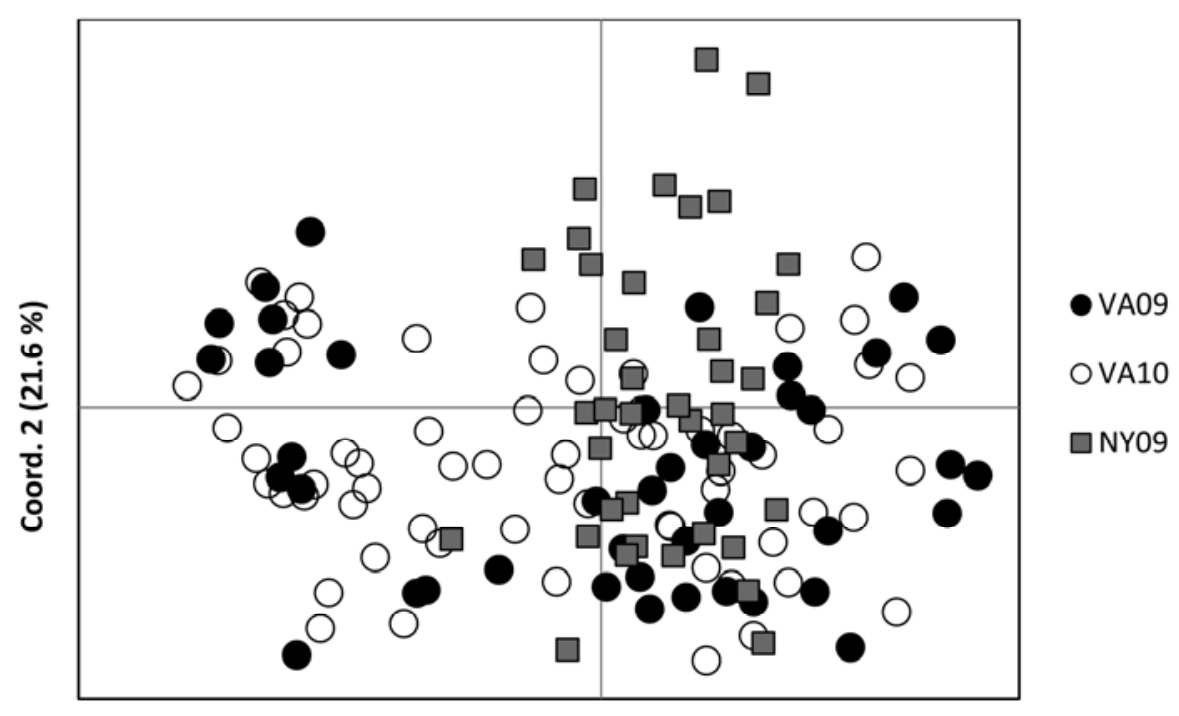

Coord. 1 (34.3\%)

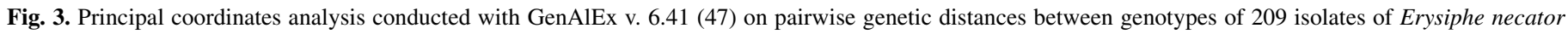

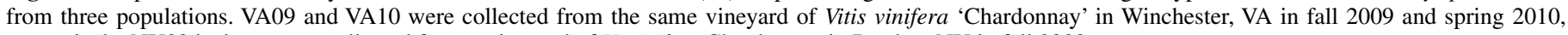
respectively. NY09 isolates were collected from a vineyard of V. vinifera Chardonnay in Burdett, NY in fall 2009. 
tance alleles during the asexual phase also results in selection of clones, some of which might increase markedly in frequency. Future studies would be needed to address whether dominant clones of E. necator at the end of the epidemic have greater fitness due to fungicide resistance or other traits that affect fitness, such as adaptation to environmental conditions or better dispersal abilities. Alternatively, dominant clones could be due to genetic drift resulting from chance colonization events of ascospores early in the epidemic. Ascospores of E. necator are released over the course of many weeks, between bud break and anthesis, when environmental conditions are favorable (22). Genotypes of colonies derived from ascospores that are established early will have more generations of asexual reproduction than genotypes that are established later.

Another potential cause of LD is population admixture; for example, sampling genetically different subpopulations and analyzing them as one population. Limited dispersal of E. necator within a vineyard could contribute to LD because of admixture. If random mating occurs only within clusters representing spatially restricted genetic neighborhoods, then population admixture will give the effect of inbreeding and lead to LD when assessed across the entire population $(9,38,66)$. We found spatial aggregation of genotypes in both vineyards at the end of the epidemics, although spatial structure was no longer detected in the New York population when clonal aggregation was eliminated from the analyses. Mantel correlations between physical and genetic distances were significant for both populations; isolates sampled from relatively short distances apart were more similar to each other than expected at random. Spatial autocorrelation is indicative of some degree of isolation by distance or subdivision into genetic neighborhoods on a small scale within vineyards. This pattern most likely arose because of restricted dispersal distances; longerdistance dispersal would be expected to lead to random mixing of genotypes and no detectable spatial structure. In the VA09 population, genotypes were more similar to each other than by chance up to $42 \mathrm{~m}$ apart, whereas NY09 significant aggregation occurred only up to $3 \mathrm{~m}$. These differences in cluster sizes could be due to differences in sampling patterns. The Virginia vineyard was rectangular in shape, with three rows approximately $100 \mathrm{~m}$ long, whereas the New York vineyard was sampled earlier in a square pattern, approximately 30 by $30 \mathrm{~m}$ (Fig. 1). Other factors that could contribute to the differences in cluster sizes are that the Virginia vineyard is a small research vineyard with few other grapevines nearby, whereas powdery mildew samples from the New York vineyard came from part of a large commercial vineyard in the Finger Lakes Region, which is a large grape production area. Additionally, the presence of a single dominant clone in New York versus several clones represented by fewer individuals in Virginia may have contributed to the differences in cluster sizes detected. Despite the many differences in details between New York and Virginia samples, the important result is finding significant spatial autocorrelation at a small scale, within vineyards.

Unlike other studies that investigated the large-scale geographic structure of $E$. necator in the eastern United States $(9,21)$, we did not detect population structure between vineyards in New York and Virginia. Similarly, we found no differences in allele frequencies in the fall and spring populations from the same vineyard (VA09 and VA10), suggesting that the overwintering bottleneck is not small enough to affect this population. Although the allele frequencies were not different between VA09 and VA10, we did not find the same genotypes between years because initial inoculum each year is from ascospores produced by sexual reproduction; similar inferences were made for other plant pathogens when the same genotypes were not found between years $(12,31)$. Studying the population structure of E. necator representative of the ascospore population prior to the contribution of asexual reproduction was challenging because of the difficulty of finding powdery mildew colonies in vineyards in the spring. Many commercial vineyards are managed aggressively with fungicides early in the spring so that there are almost no colonies present at ascospore release, preventing an analysis of all potential combinations in offspring. We attempted to sample individuals derived from ascospores by placing unsprayed trap plants in the New York vineyard when ascospores were being released; however, no colonies were observed (data not shown). Research vineyards, like the one we sampled in Virginia, may be an alternative because they usually have nonsprayed control plots. However, research plots that have been inoculated with E. necator are not suitable because population structure could potentially be biased by the influx of a few inoculated genotypes.

We are fairly confident that the LD detected in this study is not due to close linkage of markers on the same chromosomes because very few pairs of these markers were in LD at the broad geographic scale (21). Additionally, the markers were obtained haphazardly from transcriptome sequence and are not likely to be physically linked by chance in a large genome; the three sequenced powdery mildew genomes are estimated to be 120 to $160 \mathrm{MB}$ in size (58). Ideally, sexual crosses would be constructed to determine whether markers are genetically linked. However, despite repeated attempts, we have not been able to obtain enough viable progeny from crosses of $E$. necator to evaluate recombination and segregation of alleles at these EST-SSR loci.

We further hypothesize that a mixed reproductive mode combined with short-distance dispersal is likely contributing to LD in $E$. necator. We speculate that $\mathrm{LD}$ persists in populations of $E$. necator because the increase in LD caused by an increase in clonal genotypes during the asexual phase is not completely broken down by an annual generation of sexual reproduction. LD between unlinked loci can only decay by a maximum of $50 \%$ with recombination in one sexual generation; therefore, many of the alleles in the dominant clones are likely to remain nonrandomly associated. Inbreeding, which is directly calculated as a decrease in observed relative to expected heterozygosity (27), is difficult to measure in haploid fungi. An alternative would be to genotype the diploid phase as the composite genotype of the progeny from each cleistothecium (37). We tried to genotype ascospores from single cleistothecia from both vineyards but were not able to get reliable or consistent results, even with whole-genome amplification. We cannot rule out inbreeding as a contributor to repeated multilocus genotypes; however, the abundance of repeated genotypes in the fall samples versus the spring sample suggests that repeated multilocus genotypes are the result of asexual reproduction.

Modeling of recombination, clonal selection, drift resulting from chance colonization events, and limited dispersal in $E$. necator and other plant-pathogenic fungi may provide support for the hypothesis that LD can persist in sexual populations. Understanding how LD affects the population structure and evolution of E. necator is important for understanding the biology of this economically significant plant pathogen (22) and determining whether or not association mapping can be done in this fungus.

\section{ACKNOWLEDGMENTS}

This study was funded, in part, by Hatch project NYC-153410 and by awards from the American Wine Society Educational Foundation and American Society for Enology and Viticulture to M. T. Brewer and Vaadia-BARD Postdoctoral Fellowship Award Number FI-410-2008 from the United States-Israel Binational Agricultural Research and Development Fund (BARD) to O. Frenkel. We thank M. Nita at the Virginia Polytechnic Institute and State University, A. H. Smith, Jr., Agricultural Experiment and Extension Center in Winchester, VA, and the vineyard manager and owner of the commercial vineyard in Burdett, NY for allowing us to sample powdery mildew; and two anonymous reviewers for helpful comments on an earlier draft of the manuscript. 


\section{LITERATURE CITED}

1. Agapow, P. M., and Burt, A. 2001. Indices of multilocus linkage disequilibrium. Mol. Ecol. Notes 1:101-102.

2. Agrawal, A. F. 2006. Evolution of sex: Why do organisms shuffle their genotypes? Curr. Biol. 16:R696-R704.

3. Arnaud-Haond, S., and Belkhir, K. 2007. GenClone 1.0: A new program to analyse genetics data on clonal organisms. Mol. Ecol. Notes 7:15-17.

4. Arnaud-Haond, S., Duarte, C. M., Alberto, F., and Serrão, E. A. 2007. Standardizing methods to address clonality in population studies. Mol. Ecol. 5115-5139.

5. Barton, N. H., and Charlesworth, B. 1998. Why sex and recombination? Science 281:1986-1990.

6. Bentley, A. R., Milgroom, M. G., Leslie, J. F., Summerell, B. A., and Burgess, L. W. 2009. Spatial aggregation in Fusarium pseudograminearum populations from the Australian grain belt. Plant Pathol. 58:2332.

7. Bogacki, P., Keiper, F. J., and Oldach, K. H. 2010. Genetic structure of South Australian Pyrenophora teres populations as revealed by microsatellite analyses. Fungal Biol. 114:834-841.

8. Brewer, M. T., Cadle-Davidson, L., Cortesi, P., Spanu, P. D., and Milgroom, M. G. 2011. Identification and structure of the mating-type locus and development of PCR-based markers for mating type in powdery mildew fungi. Fungal Genet. Biol. 48:704-713.

9. Brewer, M. T., and Milgroom, M. G. 2010. Phylogeography and population structure of the grape powdery mildew fungus, Erysiphe necator, from diverse Vitis species. BMC Evol. Biol. 10:268.

10. Brown, A. D. H., Feldman, M. W., and Nevo, E. 1980. Multilocus structure of natural populations of Hordeum spontaneum. Genetics 96:523536.

11. Brown, J. K. M., and Wolfe, M. S. 1990. Structure and evolution of a population of Erysiphe graminis f. sp. hordei. Plant Pathol. 39:376-390.

12. Chen, R.-S., Boeger, J. M., and McDonald, B. A. 1994. Genetic stability in a population of a plant pathogenic fungus over time. Mol. Ecol. 3:209218.

13. Cortesi, P., Bisiach, M., Ricciolini, M., and Gadoury, D. M. 1997. Cleistothecia of Uncinula necator: An additional source of inoculum in Italian vineyards. Plant Dis. 81:922-926.

14. Cortesi, P., Ottaviani, M.-P. P., and Milgroom, M. G. 2004. Spatial and genetic analysis of a flagshoot subpopulation of Erysiphe necator in Italy. Phytopathology 94:544-550.

15. Dale, A. L., Lewis, K. J., and Murray, B. W. 2011. Sexual reproduction and gene flow in the pine pathogen Dothiostroma septosporum in British Columbia. Phytopathology 101:68-76.

16. Délye, C., Laigret, F., and Corio-Costet, M. F. 1997. RAPD analysis provides insight into the biology and epidemiology of Uncinula necator. Phytopathology 87:670-677.

17. Dutech, C., Rossi, J.-P., Fabreguettes, O., and Robin, C. 2008. Geostatistical genetic analysis for inferring the dispersal pattern of a partially clonal species: Example of the chestnut blight fungus. Mol. Ecol. 17:4597-4607.

18. Elliot, C. G. 1994. Reproduction in Fungi. Chapman and Hall, London.

19. Evans, K. J., Whisson, D. L., and Scott, E. S. 1996. An experimental system for characterizing isolates of Uncinula necator. Mycol. Res. 100:675-680.

20. Felsenstein, J. 1965. The effect of linkage on directional selection. Genetics 52:349-363.

21. Frenkel, O., Portillo, I., Brewer, M. T., Péros, J. P., Cadle-Davidson, L., and Milgroom, M. G. 2012. Development of microsatellite markers from the transcriptome of Erysiphe necator for analysing population structure in North America and Europe. Plant Pathol. 61:106-119.

22. Gadoury, D. M., Cadle-Davidson, L., Wilcox, W. F., Dry, I. B., Seem, R. C., and Milgroom, M. G. 2011. Pathogen profile Grapevine powdery mildew (Erysiphe necator): A fascinating system for the study of the biology, ecology and epidemiology of an obligate biotroph. Mol. Plant Pathol. 13:1-16.

23. Gadoury, D. M., and Pearson, R. C. 1990. Ascocarp dehiscence and ascospore discharge in Uncinula necator. Phytopathology 80:393-401.

24. Gadoury, D. M., and Pearson, R. C. 1991. Heterothallism and pathogenic specialization in Uncinula necator. Phytopathology 81:1287-1293.

25. Germain, H., Bergeron, M.-J., Bernier, L., Laflamme, G., and Hamelin, R. C. 2009. Patterns of colonization and spread in the fungal spruce pathogen Onnia tomentosa. Mol. Ecol. 18:4422-4433.

26. Grove, G. G. 2004. Perennation of Uncinula necator in vineyards of Eastern Washington. Plant Dis. 88:242-247.

27. Halliburton, R. 2004. Introduction to Population Genetics. Pearson Prentice Hall, Upper Saddle River, NJ.

28. Hirata, T., and Takamatsu, S. 1996. Nucleotide sequence diversity of rDNA internal transcribed spacers extracted from conidia and cleistothecia of several powdery mildew fungi. Mycoscience 37:283-288.
29. Kohli, Y., Brunner, L. J., Yoell, H., Milgroom, M. G., Anderson, J. B., Morrallj, R. A. A., et al. 1995. Clonal dispersal and spatial mixing in populations of the plant pathogenic fungus, Sclerotinia sclerotiorum. Mol. Ecol. 4:69-77.

30. Kondrashov, A. S. 1993. Classification of hypotheses on the advantage of amphimixis. J. Hered. 84:372-387.

31. Lamour, K. H., and Hausbeck, M. K. 2002. The spatiotemporal genetic structure of Phytophthora capsici in Michigan and implications for disease management. Phytopathology 91:681-684.

32. Loiselle, B. A., Sork, V. L., Nason, J., and Graham, C. 2012. Spatial genetic structure of a tropical understory shrub, Psychotria officinalis (Rubiaceae). Am. J. Bot. 82:1420-1425.

33. Mantel, N. A. 1967. The detection of disease clustering and a generalized regression approach. Cancer Res. 27:209-220.

34. Maynard Smith, J., Smith, N. H., O'Rourke, M., and Spratt, B. G. 1993. How clonal are bacteria? Proc. Natl. Acad. Sci. USA 90:4384-4388.

35. McDonald, B. A., and Linde, C. 2002. Pathogen population genetics, evolutionary potential, and durable resistance. Annu. Rev. Phytopathol. 40:349-379.

36. Miazzi, M., Natale, P., Pollastro, S., and Faretra, F. 1997. Handling of the biotrophic pathogen Uncinula necator (Schw.) Burr. under laboratory conditions and observations on its mating system. J. Plant Pathol. 79:7177.

37. Milgroom, M. G. 1995. Population biology of the chestnut blight fungus, Cryphonectria parasitica. Can. J. Bot. 73:311-319.

38. Milgroom, M. G. 1996. Recombination and the multilocus structure of fungal populations. Annu. Rev. Phytopathol. 34:457-477.

39. Milgroom, M. G., and Lipari, S. E. 1995. Population differentiation in the chestnut blight fungus, Cryphonectria parasitica, in eastern North America. Phytopathology 85:155-160.

40. Milgroom, M. G., and Lipari, S. E. 1995. Spatial analysis of nuclear and mitochondrial RFLP genotypes in populations of the chestnut blight fungus, Cryphonectria parasitica. Mol. Ecol. 4:633-642.

41. Milgroom, M. G., Lipari, S. E., and Powell, W. 1992. DNA fingerprinting and analysis of population structure in the chestnut blight fungus, Cryphonectria parasitica. Genetics 131:297-306.

42. Montarry, J., Cartolaro, P., Delmotte, F., Jolivet, J., and Willocquet, L. 2008. Genetic structure and aggressiveness of Erysiphe necator populations during grapevine powdery mildew epidemics. Appl. Environ. Microbiol. 74:6327-6332.

43. Muller, H. J. 1964. The relation of recombination to mutational advance. Mutat. Res. 1:2-9.

44. Nei, M. 1972. Genetic distance between populations. Am. Nat. 106:283392.

45. Núñez, Y., Gallego, J., Ponz, F., and Raposo, R. 2006. Analysis of population structure of Erysiphe necator using AFLP markers. Plant Pathol. 55:650-656.

46. Parks, J. C., and Werth, C. R. 1993. A study of spatial features of clones in a population of bracken fern, Pteridium aquilinum (Dennstaedtiaceae). Am. J. Bot. 80:537-544.

47. Peakall, R., and Smouse, P. E. 2006. GENALEX 6: Genetic analysis in Excel. Population genetic software for teaching and research. Mol. Ecol. Notes 6:288-295.

48. Peakall, R., Smouse, P. E., and Huff, D. R. 1995. Evolutionary implications of allozyme and RAPD variation in diploid populations of dioecious buffalograss Buchloë dactyloides. Mol. Ecol. 135-148.

49. Pearson, R. C., and Gadoury, D. M. 1987. Cleistothecia the source of primary inoculum for grape powdery mildew in New York USA. Phytopathology 77:1509-1514.

50. Pearson, R. C., and Gaertel, W. 1985. Occurrence of hyphae of Uncinula necator in buds of grapevine. Plant Dis. 69:149-151.

51. Péros, J. P., Troulet, C., Guerriero, M., Michel-Romiti, C., and Notteghem, J. L. 2005. Genetic variation and population structure of the grape powdery mildew fungus, Erysiphe necator, in southern France. Eur. J. Plant Pathol. 113:407-416.

52. Picard, D., and Plantard, O. 2006. What constitutes a population for the plant parasitic nematode Globodera pallida in its native area (Peru)? Int. J. Parasitol. 36:115-122.

53. Rousset, F. 2008. Genepop'007: A complete reimplementation of the Genepop software for Windows and Linux. Mol. Ecol. Resour. 8:103-106.

54. Schmale, D. G., Leslie, J. F., Zeller, K. A., Saleh, A. A., Shields, E. J., and Bergstrom, G. C. 2006. Genetic structure of atmospheric populations of Gibberella zeae. Phytopathology 96:1021-1026.

55. Schuelke, M. 2000. An economic method for the fluorescent labeling of PCR fragments. Nat. Biotechnol. 18:233-234.

56. Smouse, P. E., Long, J. C., and Sokal, R. R. 1986. Multiple regression and correlation extensions of the Mantel test of matrix correspondence. Syst. Zool. 35:627-632

57. Smouse, P. E., and Peakall, R. 1999. Spatial autocorrelation analysis of multi-allele and multi-locus genetic microstructure. Heredity 82:561-573. 
58. Spanu, P. D., Abbott, J. C., Amselem, J., Burgis, T. A., Soanes, D. M., Stüber, K., et al. 2010. Genome expansion and gene loss in powdery mildew fungi reveal tradeoffs in extreme parasitism. Science 330:15431546.

59. Stenberg, P., Lundmark, M., and Saura, A. 2003. MLGsim: A program for detecting clones using a simulation approach. Mol. Ecol. Notes 3:329331.

60. Stummer, B. E., Zanker, T., Scott, E. S., and Whisson, D. L. 2000. Genetic diversity in populations of Uncinula necator: Comparison of RFLP- and PCR-based approaches. Mycol. Res. 104:44-52.

61. Travadon, R., Smith, M. E., Fujiyoshi, P., Douhan, G. W., Rizzo, D. M., and Baumgartner, K. 2012. Inferring dispersal patterns of the generalist root fungus Armillaria mellea. New Phytol. 193:959-969.

62. Wahlund, S. 1928. Zusammensetzung von populationen und korrelationserscheinungen vom standpunkt der vererbungslehre aus betrachtet. Hereditas 11:65-106.
63. Walsh, P. S., Metzger, D. A., and Higuchi, R. 1991. Chelex 100 as a medium for simple extraction of DNA for PCR-based typing from forensic material. BioTechniques 10:506-513.

64. Wolfe, M. S. 1984. Trying to understand and control powdery mildew. Plant Pathol. 33:451-466.

65. Wong, F. P., and Wilcox, W. 2002. Sensitivity to azoxystrobin among isolates of Uncinula necator: Baseline distribution and relationship to myclobutanil sensitivity. Plant Dis. 86:394-404.

66. Wright, S. 1943. Isolation by distance. Genetics 28:114-138.

67. Zeller, K. A., Bowden, R. L., and Leslie, J. F. 2004. Population differentiation and recombination in wheat scab populations of Gibberella zeae from the United States. Mol. Ecol. 13:563-571.

68. Zhan, J., Pettway, R. E., and McDonald, B. A. 2003. The global genetic structure of the wheat pathogen Mycosphaerella graminicola is characterized by high nuclear diversity, low mitochondrial diversity, regular recombination, and gene flow. Fungal Genet. Biol. 38:286-297. 